\title{
Investigations on Terminalia Arjuna Fruits: Part 1- Isolation of Comounds from Petroleum Ether Fractions
}

\author{
M. Zahurul Haque, ${ }^{\text {a }}$ M. Abdullah As Saki, ${ }^{b}$ M. Umar Ali,b \\ M. Yusuff Alib and M. Abdullah-Al Maruf ${ }^{b}$ \\ aBCSIR Laboratories, Rajshahi-6206 and bepartment of Chemistry, \\ Rajshahi University, Rajshahi-6205, Bangladesh
}

\begin{abstract}
Arjun (Terminalia arjuna) is a source of many potent, biologically active compounds, planned all over Bangladesh. The chemical examinations of its fruits were taken up to isolate and identify active principles. For this purpose fresh fruits of Terminalia arjuna were extracted with rectified spirit. The extract was then triturated with petroleum ether $\left(40-60^{\circ} \mathrm{C}\right)$, which was then subjected to column chromatographic separation followed by PTLC. Such separation led to the isolation of some new pure compounds, TA-1 to TA-5. The structures of compounds were characterized through spectroscopic studies (IR, ${ }^{1} \mathrm{H}-\mathrm{NMR}$ and ${ }^{13} \mathrm{C}-\mathrm{NMR}$ ).
\end{abstract}

Key words : Arjun, TA-1, TA-5, Spectroscopic studies

\section{Introduction}

Bangladesh being situated in the monsoon area of the world is a good treasure of indigenous plants of various families and they are grown widely in forests, jungles, hillocks and gardens. Different segments of the plants such as roots, stems, leaves, barks, flowers, seeds etc., may be an interesting and important research area for the natural product chemists. These segments are used directly by the Hakims, Kabirages and Vaidays as the medicine of various diseases, since the ancient times. But they are using the different parts of the plants without having enough scientific knowledge on them. Actually they do not know what are the constituents contained in the plants and which constituents are responsible for the cure of the diseases, or possesses harmful effects for the body. A number of plants used by the Hakims, Kabirages and Viadays may contain toxic constituents, which have some health hazard associated with them and may sometimes cause serious sufferings. In this situation a systematic investigation on the available plant resources is more important. Here one thing is very encouraging to note that our country abounds with a vast majority of medicinal plants and herbs. The availability 
of medicinal plants demands a systematic investigation on the isolation, purification and characterization of physiologically active principles, which are actually useful for the treatment of various diseases. So, efforts have been made to investigate Terminalia arjuna, a medicinal plant available in Bangladesh. Terminalia arjuna belongs to the genus Terminalia (Ghani. 1998) and family Combretaceae and locally known as "Arjun gachh". Different parts of the plant are being used for the treatment of different diseases. Every part of the plant like fruits, barks and leaves contain various compounds like tannin, saponin, ester, sugar, steroids, acids and minerals (Kiritiker and Basu 1987, The Wealth of India, 1976). The present paper describes the isolation and characterization of petroleum ether triturate of Terminalia arjuna fruits.

\section{Materials and Methods}

\section{Extraction of the fruits of Arjuna with recti- fied spirit}

The powders of the fruits $(4 \mathrm{Kg}$ ) were immersed in sufficient quantity of distilled rectified spirit at room temperature for 48 hours. The extract was collected and the process of extraction was repeated five times more with fresh rectified spirit until the extract become almost colorless. The extracts were combined and concentrated by removal of the solvent in a rotary evaporator under reduced pressure at a temperature below $45^{\circ} \mathrm{C}$. A greenish gummy mass was obtained and was denoted as R.

Preliminary fractionation of the crude extract, $\mathbf{R}$

The concentrated rectified spirit extract; R was extracted with petroleum ether $(200 \mathrm{ml})$. The petroleum ether layer was of greenish colour and separated with the help of a separatory funnel and extraction was repeated for five times more. The petroleum ether extract was freed from water using anhydrous $\mathrm{Na}_{2} \mathrm{SO}_{4}$ and evaporated to dryness under reduced pressure. A deep greenish gummy mass was obtained which was denoted as mass RP (12 g).

\section{Examination of petroleum ether extract mass- RP}

The deep greenish gummy Mass RP was completely soluble in petroleum ether and partially soluble in benzene, toluene, chloroform and ethyl acetate. TLC examination on silica gel plate in different solvent system showed the fraction to be a mixture of compounds. The resolution was best obtained in toluene: chloroform (1:1) which showed three spots at $\mathrm{R}_{\mathrm{f}} 0.98,0.61$ and 0.48 with long tailing.

\section{Column chromatographic separation of the} mass RP

Mass RP (12 g) was dissolved in petroleum ether and then adsorbed in small quantity of silica gel. The adsorbed mass was evaporated to dryness under reduced pressure making 
it completely free from solvent. It was then carefully poured on the top of a column of silica gel made in toluene. The column was eluted first with toluene followed by mixtures of toluene and chloroform. Fractions were collected in $100 \mathrm{ml}$ conical flasks and examined by TLC.
The results of the chromatographic separation are shown in the Table I.

\section{Purification of fraction $\mathrm{RPF}_{1}$}

It was purified by passing through a small column of silica gel made in petroleum ether and eluted with same solvent and showed a

Table I. Column chromatographic separation of fraction RP

\begin{tabular}{|c|c|c|c|c|}
\hline $\begin{array}{l}\text { Collection. } \\
\text { Nos }\end{array}$ & Eluting solvent & TLC examination & Observation & $\begin{array}{c}\text { Fraction } \\
\text { nos. }\end{array}$ \\
\hline $1-3$ & Toluene $100 \%$ & $\begin{array}{l}\text { One single spot at } \mathrm{R}_{\mathrm{f}} 0.98 \\
\text { with small tailing near } \\
\text { baseline }\end{array}$ & $\begin{array}{l}\text { One pure compound } \\
\text { with impurities }\end{array}$ & $\mathrm{RPF}_{1}$ \\
\hline $4-7$ & $\begin{array}{l}\text { Toluene } 100 \% \\
0.92 \text { and } 0.78\end{array}$ & $\begin{array}{l}\text { Three spots at } R_{\mathrm{f}} 0.98 \text {, . } \\
\text { three compounds. }\end{array}$ & Mixtures of at list & $\mathrm{RPF}_{2}$ \\
\hline $8-10$ & $\begin{array}{l}\text { Toluene : } \\
\text { Chloroform (10:1) }\end{array}$ & One single spot at $R_{f} 0.78$ & One pure compound & $\mathrm{RPF}_{3}$ \\
\hline $11-17$ & $\begin{array}{l}\text { Toluene : } \\
\text { Chloroform (5:1) }\end{array}$ & Tailing from the base line & No good resolution & $\mathrm{RPF}_{4}$ \\
\hline $18-25$ & $\begin{array}{l}\text { Toluene : } \\
\text { Chloroform (1:1) }\end{array}$ & Tailing from the base line & No good resolution & $\mathrm{RPF}_{5}$ \\
\hline $25-31$ & $\begin{array}{l}\text { Toluene : } \\
\text { Chloroform(1:1) }\end{array}$ & $\begin{array}{l}\text { One spot at } R_{f} 0.61 \\
\text { with tailing. }\end{array}$ & $\begin{array}{l}\text { One compound } \\
\text { with impurities }\end{array}$ & $\mathrm{RPF}_{6}$ \\
\hline $32-37$ & $\begin{array}{l}\text { Toluene : } \\
\text { Chloroform (2:3) }\end{array}$ & Spot near base line & No good resolution & $\mathrm{RPF}_{7}$ \\
\hline $38-45$ & $\begin{array}{l}\text { Toluene: } \\
\text { Chloroform (1:3) }\end{array}$ & $\begin{array}{l}\text { Tailing from the base line } \\
\text { Spot near base line }\end{array}$ & No good resolution & $\mathrm{RPF}_{8}$ \\
\hline $46-50$ & $\begin{array}{l}\text { Chloroform } 100 \% \\
\text { with small tailing }\end{array}$ & One spot at $R_{f} 0.37$ & $\begin{array}{l}\text { One compound } \\
\text { with impurities }\end{array}$ & $\mathrm{RPF}_{9}$ \\
\hline $51-55$ & $\begin{array}{l}\text { Chloroform : } \\
\text { Ethyl acetate (10:1) }\end{array}$ & Tailing from the base line & No good resolution & $\mathrm{RPF}_{10}$ \\
\hline $56-60$ & $\begin{array}{l}\text { Chloroform : } \\
\text { Ethyl acetate (8:1) }\end{array}$ & Tailing from the base line & No good resolution & $\mathrm{RPF}_{11}$ \\
\hline $61-65$ & $\begin{array}{l}\text { Chloroform : } \\
\text { Ethyl acetate (5:1) }\end{array}$ & One major spot at $R_{f} 0.48$ & $\begin{array}{l}\text { One compound } \\
\text { with impurities }\end{array}$ & $\mathrm{RPF}_{12}$ \\
\hline
\end{tabular}


single spot at $\mathrm{R}_{\mathrm{f}} 0.98$ in petroleum ether (40$60^{\circ} \mathrm{C}$ ). It was a white waxy solid and melted at $65-67^{\circ} \mathrm{C}$. The compound was soluble in petroleum ether, toluene, benzene and chloroform. It was designated at TA-1.

Similarly, the other fractions, $\mathrm{RPF}_{3}, \mathrm{RPF}_{6}$, $R P F_{9}$ and $R P F_{12}$ were purified and the isolated compounds were denoted as TA-2, TA-3, TA-4 and TA-5 respectively.

\section{Results and Discussion}

\section{Study on the fraction $\mathrm{RPF}_{1}$ (compound TA-1)}

The compound TA-1 was a waxy solid, melted at $65-67^{\circ} \mathrm{C}$ and soluble in petroleum ether, chloroform and ethyl acetate.

The IR Spectrum of the compound TA-1 showed sharp bands at 2920 and $2848 \mathrm{~cm}^{-1}$ for C-H stretching vibration, 1470 and 1378 $\mathrm{cm}^{-1}$ for $\mathrm{C}-\mathrm{H}$ bending vibration and for rocking vibration. These absorptions are characteristics for long alkyl chains. The hydrocarbon nature of the compound was further confirmed by ${ }^{1} \mathrm{H}-\mathrm{NMR}$ spectrum, which showed a triplet at $\delta 0.89$ for the terminal methyl protons and a huge unsplit singlet at $\delta 1.27$ for methylene protons of long alkyl chain. The high intensity at $\delta 1.27$ suggested the presence of a long alkyl chain. The high intensity at $\delta 1.27$ suggested the presence of large number of methylene protons. It may therefore be concluded that TA- 1 is a hydrocarbon. The m.p. of $\mathrm{TA}-1,65-67^{\mathrm{O}} \mathrm{C}$ is more close to that of Hentriacontane (Ahmad et al. 1982). The structure of Hentriacontane is shown below:

$$
\mathrm{CH}_{3}-\left(\mathrm{CH}_{2}\right)_{29}-\mathrm{CH}_{3}
$$

\section{Study on the fraction $\mathrm{RPF}_{3}$ (compound TA-2)}

The compound TA-2 was an amorphous solid, melted at $70-72^{\circ} \mathrm{C}$ and soluble in petroleum ether, chloroform and ethyl acetate. It responded to hydroxamic acid test of ester. The IR spectrum of the compound TA-2 showed sharp absorption band at 2918 and $2848 \mathrm{~cm}^{-1}$ due to presence of C-H (aliphatic) asymmetric and symmetric stretching vibrations respectively. The absorption band at $1712 \mathrm{~cm}^{-1}$ was due to $>\mathrm{C}=\mathrm{O}$ group. Absorption band at $1461 \mathrm{~cm}^{-1}$ was due to $-\mathrm{CH}_{3}$ bending vibration. It also showed C-O stretching at $1217 \mathrm{~cm}^{-1}$. From this information the compound TA-2 was assumed to be an ester. The compound TA-2 was isolated in too small quantity to carry out further investigation, on it and was not possible to elucidate the structure of the compound.

\section{Study on the fraction $\mathrm{RPF}_{6}$ (compound TA-3)}

The compound TA-3 was a waxy solid, melted at $60-62^{\circ} \mathrm{C}$ and soluble in petroleum ether, chloroform and ethyl acetate. The IR spectrum of the compound TA-3 showed absorption band at $3490 \mathrm{~cm}^{-1}$ due to $-\mathrm{OH}$ group. Absorption bands at 2917 and 2848 
$\mathrm{cm}^{-1}$ due to aliphatic - $\mathrm{CH}$ asymmetric and symmetric vibrations. Absorption band at $1738 \mathrm{~cm}^{-1}$ due to $>\mathrm{C}=\mathrm{O}$ group. Weak absorption band at $1652 \mathrm{~cm}^{-1}$ due to isolated $\mathrm{C}=\mathrm{C}$ band. Absorption band at 1462 and $1378 \mathrm{~cm}^{-1}$ due to $-\mathrm{CH}_{2}$ - and $-\mathrm{CH}_{3}$ bending.

The ${ }^{1} \mathrm{H}-\mathrm{NMR}$ spectrum and ${ }^{13} \mathrm{C}$-NMR spectrum of the compound TA-3 could not be analyzed with confidence. Therefore characterization of this compound was not further pursued.

\section{Studies on the fraction $\mathrm{RPF}_{9}$ (compound TA-4)}

The compound TA-4 was a white needle shaped crystalline substance. It melted at $136-137^{\circ} \mathrm{C}$.and was soluble in chloroform, ethyl acetate and acetone. It positively responded to Salkowsky and LibermannBurchard colour reaction. The IR spectrum of TA-4 showed an absorption band at 3500 $\mathrm{cm}^{-1}$ due to $-\mathrm{OH}$ group. Absorption bands at 2931 and $2850 \mathrm{~cm}^{-1}$ due to aliphatic -CH asymmetric and symmetric vibrations. Absorption band at $1710 \mathrm{~cm}^{-1}$ was due to $>\mathrm{C}=\mathrm{O}$ group. Weak absorption band at 1653 $\mathrm{cm}^{-1}$ was due to isolated $\mathrm{C}=\mathrm{C}$ band. Absorption band at $1464 \mathrm{~cm}^{-1}$ was due to $-\mathrm{CH}_{2}$ - bending.

The ${ }^{1} \mathrm{H}-\mathrm{NMR}$ spectrum of compound TA-4 in $\mathrm{CDCl}_{3}$ has two sharp singlet at $1.00(3 \mathrm{H}$, s) and 1.25 (3H, s) ppm. These indicated the presence of two angular methyl protons at C18 and $\mathrm{C}-19$ respectively. Three doublets at $\mathrm{d}$ 0.93 (6H, d, J=8.0 Hz), 0.68 (3H, d, J=7.26
$\mathrm{Hz})$ and $0.81(6 \mathrm{H}, \delta, \mathrm{J}=4.8 \mathrm{~Hz})$, were for the methyl protons of $\mathrm{C}-21, \mathrm{C}-26$ and $\mathrm{C}-27$ respectively which were attached to methine carbons. A multiplet at $\delta 0.84 \mathrm{ppm}$ was accounted for methyl protons of C-29 were attached to a methylene group. The ${ }^{13} \mathrm{C}$ NMR spectrum of the compound TA-4 (Fig. 4.15 to 4.18, Table-4.2) in $\mathrm{CDCl}_{3}$ exhibited the signals at $\delta 140.91$ and $121.87 \mathrm{ppm}$ were due to olefinic carbons in the ring system. The most deshielded chemical shift at $\delta$ 140.91 ppm was due to the quaternary carbon.

The signal at $\delta 71.96$ was assigned to oxymethine carbon. The signals of $\delta 12.01$ (C-18), 19.54 (C-19), 18.93 (C-21), 19.84 (C-26), 19.05 (C-27), 12.28 (C-29) ppm were due to six methyl groups of compound TA-4.

The deshielded signals at $\mathrm{d} 36.30$ (C-10) and $\delta 42.33(\mathrm{C}-13)$ ppm were due to quaternary carbons $(>\mathrm{C}<)$.

The DEPT-135 spectra displayed eleven methylene carbons at $\delta 37.41(\mathrm{C}-1), 31.82$ (C-2), 42.25 (C-4), 31.94 (C-7), 21.10 (C11), 39.93 (C-12), 24.33 (C-15), 28.27 (C16), 33.96 (C-22), 26.08 (C-23), 23.08 (C28); nine methine carbons at $\delta 140.91(\mathrm{C}-4)$, 121.87 (C-5), 31.94 (C-8), 50.15 (C-9), 56.78 (C-14), 56.22 (C-17), 36.17 (C-20), 45.85 (C-24) and 29.16 (C-25).

A comparison of ${ }^{13} \mathrm{C}-\mathrm{NMR}$ spectral data of TA-4 and that reported for ß-sitosterol (Ahmed. 2002) is shown in Table II. 
Table II. A comparison of ${ }^{13} \mathrm{C}$-NMR spectral data of TA-4 and that reported for ß-sitosterol

\begin{tabular}{|c|c|c|c|}
\hline \multirow[t]{2}{*}{ Carbon number } & \multirow[t]{2}{*}{ Types of Carbon } & \multicolumn{2}{|c|}{ Chemical shift in ppm } \\
\hline & & TA-4 & ß-sitosterol \\
\hline 1 & $-\mathrm{CH}_{2-}$ & 37.41 & 37.33 \\
\hline 2 & $-\mathrm{CH}_{2^{-}}$ & 31.82 & 31.62 \\
\hline 3 & $>\mathrm{CH}-\mathrm{OH}$ & 71.96 & 71.73 \\
\hline 4 & $-\mathrm{CH}_{2^{-}}$ & 42.25 & 42.42 \\
\hline 5 & $>C=$ & 140.91 & 140.78 \\
\hline 6 & $=\mathrm{CH}-$ & 121.87 & 121.69 \\
\hline 7 & $-\mathrm{CH}_{2^{-}}$ & 31.94 & 31.91 \\
\hline 8 & $>\mathrm{CH}-$ & 31.94 & 31.91 \\
\hline 9 & $>\mathrm{CH}-$ & 50.15 & 50.16 \\
\hline 10 & $>\mathrm{C}<$ & 36.30 & 36.48 \\
\hline 11 & $-\mathrm{CH}_{2^{-}}$ & 21.10 & 21.12 \\
\hline 12 & $-\mathrm{CH}_{2^{-}}$ & 39.93 & 39.82 \\
\hline 13 & $>\mathrm{C}<$ & 42.33 & 42.33 \\
\hline 14 & $>\mathrm{CH}-$ & 56.78 & 56.79 \\
\hline 15 & $-\mathrm{CH}_{2^{-}}$ & 24.33 & 24.32 \\
\hline 16 & $-\mathrm{CH}_{2^{-}}$ & 28.27 & 28.26 \\
\hline 17 & $>\mathrm{CH}-$ & 56.22 & 56.12 \\
\hline 18 & $-\mathrm{CH}_{3}-$ & 12.01 & 11.89 \\
\hline 19 & $-\mathrm{CH}_{3}-$ & 19.54 & 19.44 \\
\hline 20 & $>\mathrm{CH}-$ & 36.17 & 36.17 \\
\hline 21 & $-\mathrm{CH}_{3}-$ & 18.93 & 18.85 \\
\hline 22 & $-\mathrm{CH}_{2-}$ & 33.96 & 33.98 \\
\hline 23 & $-\mathrm{CH}_{2^{-}}$ & 26.08 & 26.13 \\
\hline 24 & $>\mathrm{CH}-$ & 45.85 & 45.58 \\
\hline 25 & $>\mathrm{CH}-$ & 29.16 & 29.18 \\
\hline 26 & $-\mathrm{CH}_{3}-$ & 19.84 & 19.84 \\
\hline 27 & $-\mathrm{CH}_{3}-$ & 19.05 & 19.07 \\
\hline 28 & $-\mathrm{CH}_{2^{-}}$ & 23.08 & 23.09 \\
\hline 29 & $-\mathrm{CH}_{3}-$ & 12.28 & 12.33 \\
\hline
\end{tabular}


One the basis of the comparison of the various physical properties and spectral comparison of TA-4 and ß-sitosterol, the compound TA-4 was identical to be $ß$-sitosterol. The structure is represented bellow :

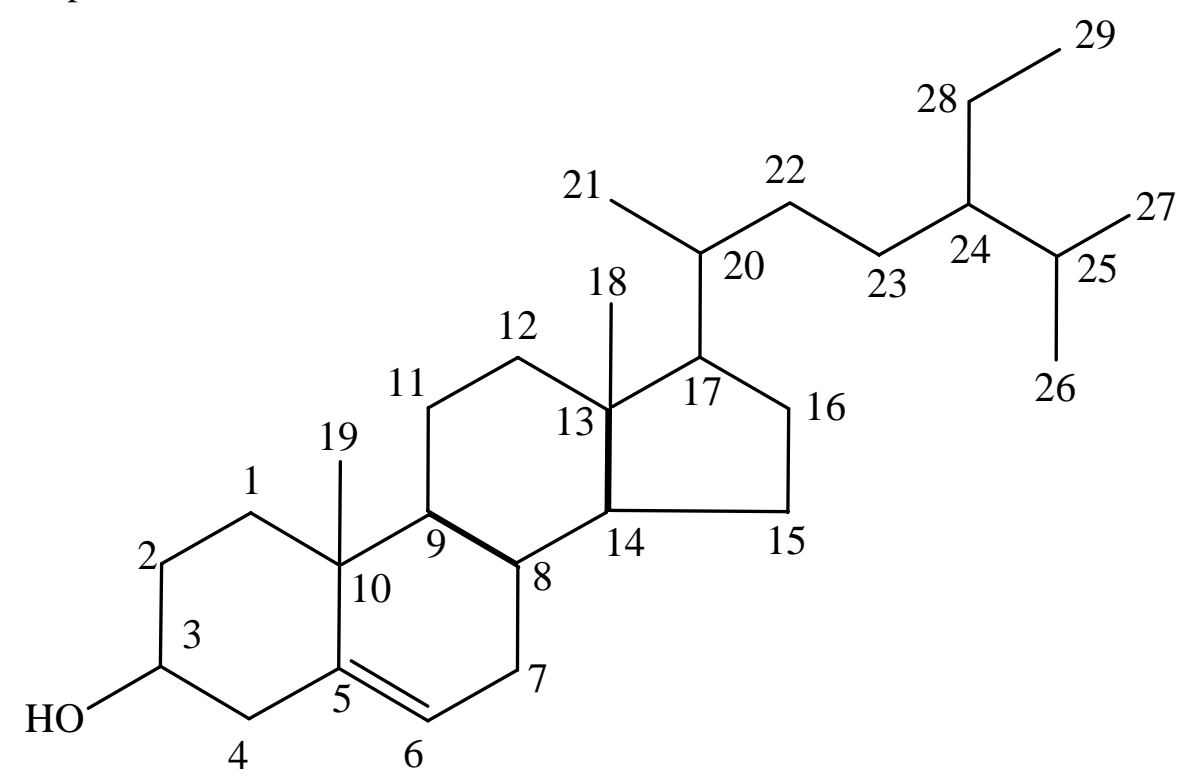

\section{ß-Sitosterol}

Study on the fraction $\mathrm{RPF}_{12}$ (compound TA-5)

Compound TA-5 was colourless crystalline compound. It melted at $108-110^{\circ} \mathrm{C}$ and was soluble in petroleum ether, chloroform and ethyl acetate.

The IR Spectrum of the compound TA-5 showed absorption bands at 3063 and 3031 $\mathrm{cm}^{-1}$ due to (aromatic) C-H. Absorption bands at 2925 and $2854 \mathrm{~cm}^{-1}$ were due to (aldehyde) C-H. Absorption band at 1698 $\mathrm{cm}^{-1}$ was due to $\mathrm{C}=\mathrm{O}$ conjugated. Absorption bands at 1602 and $1584 \mathrm{~cm}^{-1}$ were due to
$\mathrm{C}=\mathrm{C}$ group (aromatic). Absorption bands at 806 and $711 \mathrm{~cm}^{-1}$ were due to -CH (aromatic). 
studies on some medicinal plants of Pakistan, Buxus papillosa, Catharanthus roseus and Cissampelos pareira. Ph.D Thesis, H.E.J. Research Institute of Chemistry, Karachi University, Karachi, Pakistan.

Ghani, A. (1998) Medicinal Plants of Bangladesh, Chemical Constituents and Uses. Published by Asiatic Society of Bangladesh, p 304.
Kiritiker, K.R. and Basu, B.D. (1987) Indian Medicinal Plants (2nd Ed.), International Book Distributors Publications, India, 2: 1023-1028.

The Wealth of India (1976) A dictionary of Indian Raw Materials and Industrial Products, C.S.I.R New Delhi (Second Reprint), 10: 161.

Received : June 27, 2005;

Accepted : January 21, 2007 